\title{
EVOLUÇÃO PALEOGEOGRÁFICA E ESTRUTURAL DA PORÇÃO CENTRAL DA BACIA BAMBUII, NO NORTE DO ESTADO DE MINAS GERAIS
}

\author{
OMAR FERREIRA LOPES*
}

\begin{abstract}
Three large and distinct lithological sets were deposited at the center of the Bambui Basin, during the final phase of the Pre-Cambrian period, respectively characterized by exclusive carbonated (limestones and dolostones), clastic and pelitic (siltstones and mudstones) and clastic or carbonated (siltstones and black limestones) natures. In previous works, such facies have been considered as in ill-defined lateral equivalence, strictly over the region which is now occupied by São Francisco River, under its thick alluvial deposits which masks all the details of contact.

The present work establishes a characterization of the paleogeographical domains for each of the litho-stratigraphic units, which negates the suggested distribution of the facies by evidencing the complex relations exibited by them. In addition, the stratigraphic columns, proposed for the Paraopeba Formation, in the same region, cannot survive within the present model.
\end{abstract}

INTRODUÇÃo A área pesquisada encontra-se limitada pelos meridianos $44^{\circ}$ e $44^{\circ} 30^{\prime}$ e pelos paralelos $14^{\circ} 30^{\prime}$ e $16^{\circ}$, cobrindo parte dos municípios de Itacarambi e Januária (MG), no médio São Francisco (Fig. 1).

A inexistência de trabalhos sistemáticos de cartografia geológica sobre a região estudada impôs, preliminarmente, a elaboração de mapas em escalas de 1:500 000 à escala dos levantamentos de mina $(1: 100)$ (In: Lopes, $O$. F., 1979), que constituem a fonte dos problemas analisados a seguir.

\section{CONTEXTO GEOLÓGICO REGIONAL O Grupo} Bambuí apresenta-se, no setor estudado, restrito às fácies pelito-carbonatadas inferiores da Formação Paraopeba, correlacionáveis àquelas descritas originalmente sob as denominaçðes: "Sete Lagoas", "Serra de Santa Helena" e "Lagoa do Jacaré" (Costa e Branco, 1961).

Esses sedimentos, eximidos de ações metamórficas significatiyas, recobrem em franca discordância um complexo granito-gnáissico que se afigura como um domo assimétrico, com sua maior dimensão orientada segundo N-NE/S-W, localizado a oeste de Januária. $\mathrm{O}$ complexo cristalino não foi diferenciado na área estudada.

O curso atual do Rio São Francisco tem sido, na região Itacarambi-Januária, considerado como superposto a um limite entre as fácies calcário-dolomíticas e as fácies pelíticas da Formação Paraopeba (Godoy, 1957; Cassedanne, 1972 e 1973; e Fleischer e Routhier, 1970), que seria materializado sob a forma de uma estrutura positiva, contemporânea da deposição dessas fácies. Esta estrutura, essencialmente retilínea, teria sido reordenada pela superposição de múltiplos eventos tectônicos, produzindo, ao final dessa evolução, o sistema de falhas denominado "geoclase sanfranciscana" (Guimarães, 1964; e Cassedanne, 1972).

As relações de contato entre as três grandes fácies são, em verdade, mais complexas que as interpretaçðes precedentes sugerem; neste sentido, testemunham os seguintes fatos:
- A fácies calcário-dolomítica apresenta-se, aparentemente, sem nenhuma evidência de variaçðes de espessura em ambas as margens do Rio São Francisco (regióes de São Francisco e Itacarambi).

- A mesma fácies é recoberta, ainda na margem esquerda do Sẵo Francisco, por $230 \mathrm{~m}$ da sequência pelítica e pelito-carbonatada (Fig. 2).

- Os dados de uma única sondagem estratigráfica, realizada na região de Lontra (MG), pela CPRM, mostram as feiçøes de contato da unidade basal da fácies calcário-dolomítica recoberta diretamente por siltitos puros, bem classificados, evidenciando o acunhamento e disparição de cerca de $180 \mathrm{~m}$ da sequiência carbonatada exposta nas margens do Rio São Francisco.

- As fácies pelíticas ("Serra de Santa Helena") e pelitocarbonatada ("Lagoa do Jacare'") estendem-se de maneira contínua, o termo superior recobrindo, $160 \mathrm{~km}$ ao sul de Januária, nos flancos da Serra do Cabral, as sequuências metamórficas do Supergrupo Minas e os diàmictitos atribuídos ao Grupo Macaúbas (Pflug e Schöll, 1975).

- As relações espaciais de repartição das fácies, em áreas adjacentes à "geoclase", evidenciam as múltiplas feiçðes paleogeográficas que se sucederam quando da deposiçãoo da Formação Paraopeba, além do caráter essencialmente detrítico desta formação.

LITOESTRATIGRAFIA Uma coluna litoestratigráfica válida para o substrato e para toda a porçăo central da Bacia Bambuí é representada, da base para o topo (Fig. 2), pela sucessão:

EMBASAMENTO CRISTALINO Os terrenos do -embasamento, ao contrário do que se supunha até o presente, ocupam uma vasta área a oeste do segmento Itacarambi-Januária, geralmente apresentando-se cobertos por uma delgada camada de detritos produzidos pela alteração das séries de cobertura. Os principais tipos petrográficos desta unidade resumem-se a granitos à biotita, gnaisses fitados e anfibolitos; a diferenciação

* Departamento de Geologia, Universidade Federal do Paraná, Curitiba, Paraná 


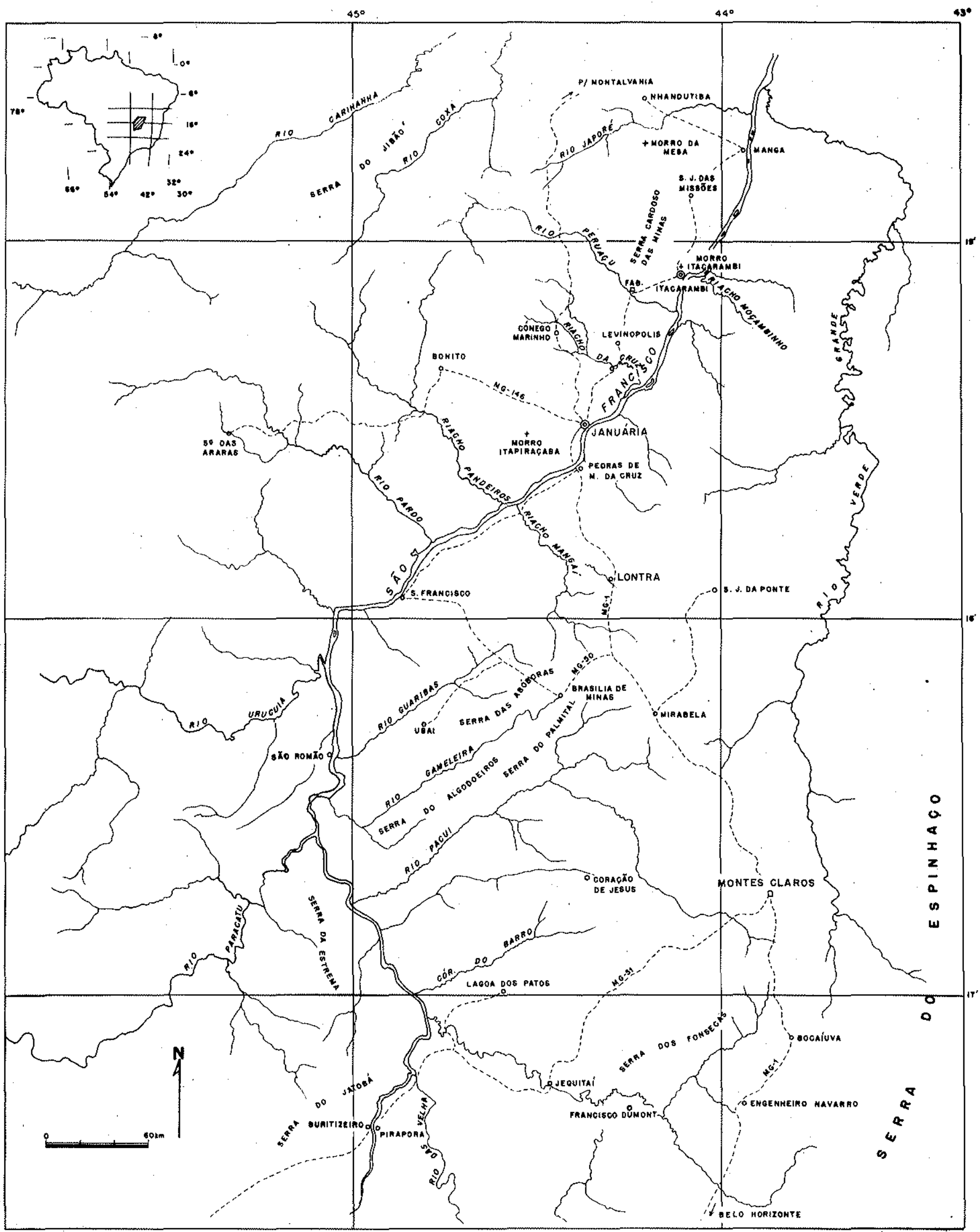

Figura 1 - Localização geográfica 


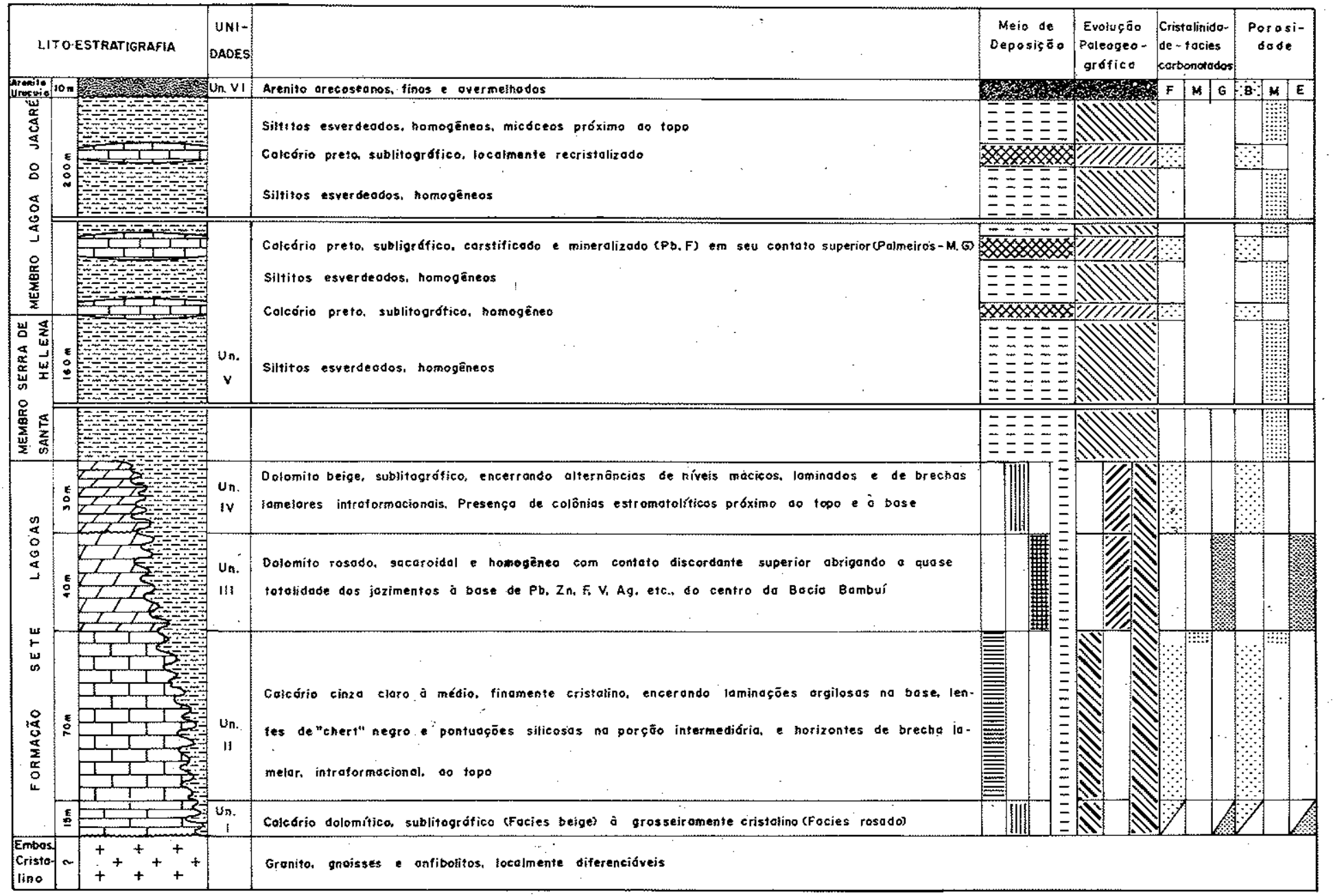

Figura 2 - Síntese evolutiva. Legenda - F: Fina; M: Média; G: Grosseira; B: Baixa; M: Média; E: Elevada; Meio continental; Meio inframaré; Meio intermaré; Meio supralitoral; Meio lagunar; Fácies pelíticos-colmatação final da bacia; Transgressão-bacia confinada; Transgressão local sobre o alto-fundo; Fácies pelíticos-centro da bacia; Transgressão-mar epicontinental; Regressão-preenchimento da bacia de deposição; Contato discordante

LEGENDA

F Fino

M Média

G Grosseira

8 8oixa

M Medio

E Elevoso

Meio continental

Meio infra-mare

IIIA Meio inter-maré

Meio supro-litorol

Meio lagunar

E习 Facies pelificos - colmotoçāo

E

NIV Transgressǟo- bacio confinado

VI] Tramsoressäo locol sobre

IIV Focies positicas - centro do bacio

Transgressāo-mar enpicontinentrot

VI] Regressāo- preenchimento do bacio de deposigäo

Contelo discordante 


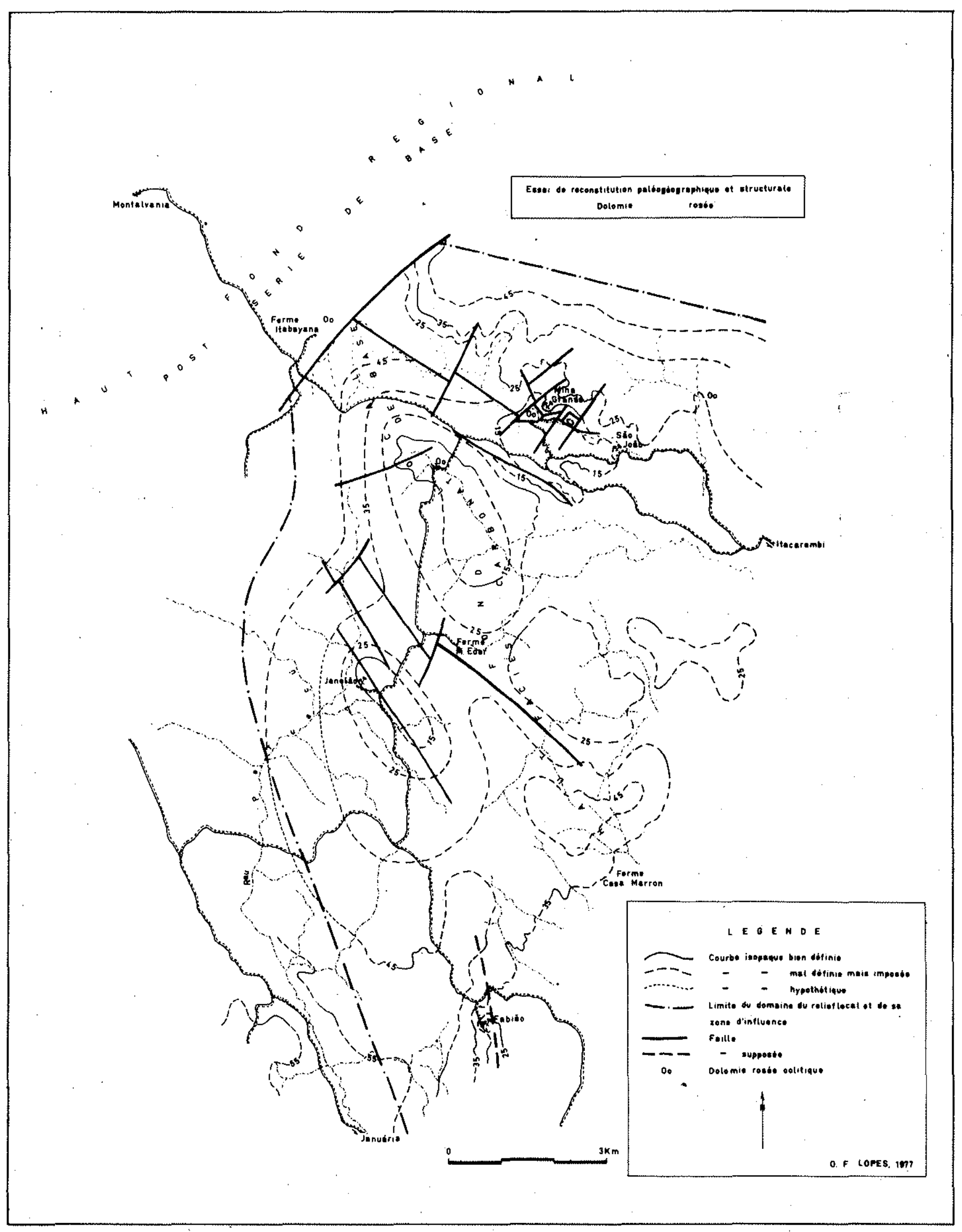

Figura 3 - Mapa de isopacas da Unidade III (Reprodução da área do “domo" de Itacarambi, em Lopes, O. F., 1979) 
dessas litologias reproduz relações complexas mesmo se analisadas pontualmente, como ocorre na região de Bonito $(\mathrm{MG})$.

O elemento estrutural constante do complexo cristalino é a foliação das rochas gnáissicas, invariavelmente orientada a $\mathrm{N} 35^{\circ} \mathrm{W} ; 70^{\circ} \mathrm{SW}$, ao longo de todo o curso do Riacho da Cruz.

A deposição da cobertura sedimentar transgressiva foi precedida de uma fase erosiva enérgica, expressa pela completa peneplanação da superficie então aflorante do embasamento, o que se deduz da regularidade na espessura dos bancos na base dessa cobertura.

\section{UNIDADE I - Calcário dolomítico bege $e$} rosado Recobrindo em franca discordância os terrenos do embasamento cristalino, esta unidade marca regionalmente a base da Formação Paraopeba; são distintas duas fácies principais no interior desta unidade, apesar de as mesmas não assumirem posiçðes estratigráficas definidas; habitualmente, elas apresentam-se sob a for. ma de alternâncias de um e outro dos tipos petrográficos distintos.

As fácies rosada e bege são maiormente representadas por tipos sublitográficos, embora a primeira possa apresentar, localmente, cristalinidade média. Assim, o tipo petrográfico mais freqüente em ambas as fácies se resume em uma massa micrítica fundamental, encerrando estruturas produzidas por recristalização incipientemente desenvolvidas.

Apesar da irregularidade na distribuição das fácies no interior da unidade, sua espessura invariável, de 15 $m$, atesta uma sedimentação homogênea na escala da bacia de deposição.

\section{UNIDADE II - Calcário cinza-claro Mostrando} feiçðes de contato nítido e concordante com a Unidade $I$, este horizonte de natureza exclusivamente calcária apresenta uma repartição interna em três fácies que são, da base ao topo:

- Calcário cinza-claro encerrando laminaçōes argilosas, totalizando 20 ou $30 \mathrm{~m}$ de espessura.

- Calcário cinza-claro, silicoso, em que a sílica se expressa sob a forma de esferas submilimétricas ou de len- tes de chert preto deci-centimétricas e concordantes à estratificação da encaixante. A espessura do horizonte é da ordem de $30 \mathrm{~m}$.

- Enfim, uma seqüếncia com até nove bancos de brecha lamelar intraformacional, com 15 ou $20 \mathrm{~m}$ de espessura.

Ocasionalmente, a Unidade II apresenta um horizonte de transição, de caráter calcário-dolomítico, aos dolomitos sobrejacentes; sua espessura máxima é de $10 \mathrm{~m}$; nesta fácies, o efeito de superposição das várias fases de recristalização produz horizontes com cristalinidade grosseira. Neste caso, são reconhecidas três geraçðes de cimento do tipo infilling cement (Dunham, 1962).

UNIDADE III - Dolomito sacaroidal rosado Esta unidade distingue-se das demais por sua excepcional porosidade e pela homogeneidade de seu tipo petrográfico fundamental, encerrando numerosas figuras de laminaçðes cruzadas e ocasionais niveis de brecha lamelar intraformacional, preservados aos eventos de recristalização, excepcionalmente intensos e numerosos nesta unidade.

Os estilolitos são unipresentes, apresentando geomew tria e disposiçðes espaciais as mais variadas, sendo sistematicamente mais antigos que a última fase de recristalização da rocha suporte, o que os caracteriza como de desenvolvimento sin-diagenético.

Mudanças impostas ao meio de sedimentação, como as evidenciadas no topo dessa unidade, são responsáveis pela variedade de microfácies observadas nesta posição estratigráfica, da dolomicrita maciça às "amas" produzidas pela agregação de cristais de calcita espática ( $\phi$ de 0,2 a $3 \mathrm{~mm}$ ).

As variações de espessura impostas pela evolução paleogeográfica desta unidade são consideráveis (de 15 a $50 \mathrm{~m}$ ), sendo determinantes do ponto de vista metalogenético, desde que se verifica a relação entre as áreas de menor espessura deste horizonte (Fig. 3) às concentraçðes minerais plombo-zincíferas conhecidas regionalmente, mais precisamente instaladas sobre a superfície carstificada fóssil que marca seu topo, da região da Serra do Ramalho (BA) à de Januária.

O contato discordante à unidade superior é localmente complexo (Fig. 4) e regionalmente recoberto por

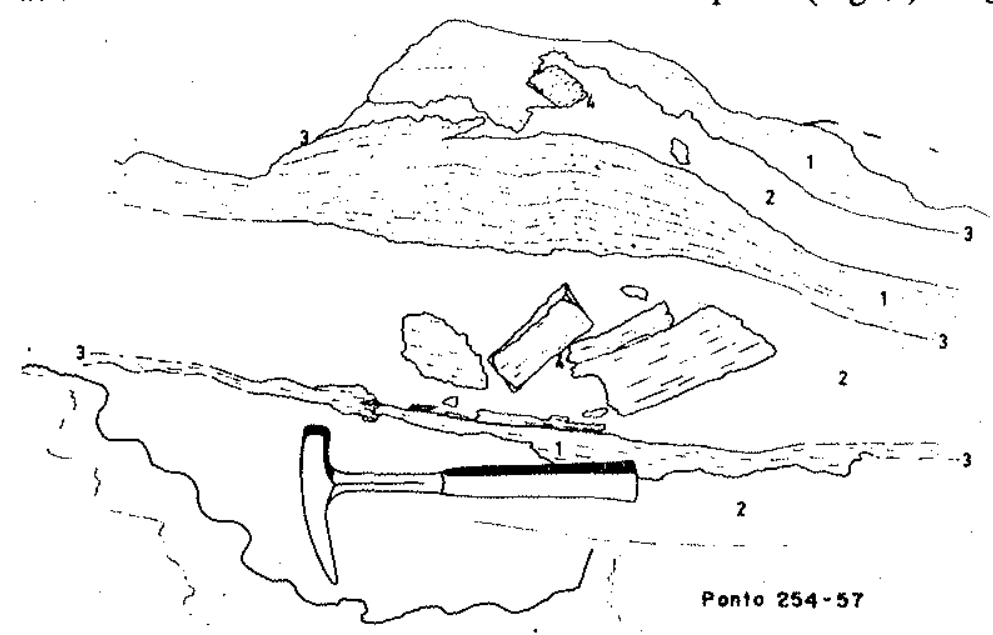

Figura 4 - Contato complexo entre as unidades III e IV. Contato feito por superfícies de erosão superpostas (3), que separam os dolomitos beges (1) dos rosados, finamente cristalinos (2). Elementos intraclásticos do dolomito bege (4) são encerrados por horizontes do dolomito rosado 
um horizonte com cerca de $1 \mathrm{~m}$ de espessura, de brecha intraformacional que encerra clastos tanto da unidade III quanto da Unidade IV.

UNIDADE IV - Dolomito sublitográfico bege Este horizonte encerra uma enorme variedade de fácies desenvolvidas a partir de um tipo petrográfico, em sua origem, extremamente homogêneo. Assim, os aspectos mais característicos ressaltados pela análise de campo resumem-se em alternâncias de fácies bréchicas com fácies laminadas, geralmente descontínuas lateralmente. As brechas lamelares, intraformacionais, apresentam a mesma natureza petrográfica para a matriz (geralmente totalizando $20 \%$ da rocha) e para os intraclastos $(80 \%$ da rocha); 'estes elementos são distintos apenas por pouco notáveis variações na cor.

Os estilolitos são numerosos e homogeneamente distribuídos por toda a unidade, ocorrendo frequientemente em posição vertical.

A expressão da sílica nesta unidade limita-se às lentes delgadas de chert preto, com até $50 \mathrm{~cm}$ de comprimento dispostas em concordância com os estratos e mais abundantes próximo ao topo da unidade.

A Unidade IV encerra freqüentemente estruturas estromatolíticas ou de esteiras de algas, estas últimas parecendo ser responsáveis pela maioria das fácies laminadas. As colônias de estromatólitos são produzidas pela agregação de indivíduos colunares simples, ligados por ramificaçðes laterais (tipo LLH de Logan et al., 1964).

Analisando ao microscópio, o dolomito bege apresenta-se constituído por uma massa micrítica fundamental ( $\phi$ menor que $0,05 \mathrm{~mm}$ ) mostrando, geralmente associados às descontinuidades estruturais da rocha, dois ou três fácies de natureza dolomicrosparríticas e dolosparríticas, produzidas pelo efeito de recristalização.

As espessuras do horizonte analisado são fortemente variáveis, raramente ultrapassando $25 \mathrm{~m}$.

$O$ contato à unidade superior é gradacional.

Os conjuntos litológicos descritos, da Unidade I à Unidade IV, apesar de apresentarem uma identidade litológica característica, correspondem em suas posiçðes estratigráficas aos sedimentos da Formação Sete Lagoas (Branco e Costa, op. cit.).

UNIDADE V - Siltitos $e$ argilitos Esta unidade é caracterizada pela extrema homogeneidade de seus tipos litológicos limitados, em sua porção aflorante, a 20 ou $30 \mathrm{~m}$ de argilitos que fazem a base, sotopostos a $70 \mathrm{~m}$ de siltitos, tal como ocorre na seção do Córrego Magaí próximo à localidade de Lontra.

Uma porção de espessura análoga à aflorante foi, na área estudada, exclusivamente identificada em sondagem, jamais aflorando ao centro da Bacia Bambuí.

Próximo ao topo de todo o pacote, a rocha é geralmente micácea à base de finas lamelas de muscovita.

A Unidade V ocupa uma posição estratigráfica correlacionável à sequêencia clástica do Membro "Serra de Santa Helena (Branco e Costa, op. cit.).

A passagem à unidade superior foi originalmente definida pelo aparecimento de corpos lenticulares de calcário preto; neste trabalho, mais que um limite estratigráfico, esses horizontes representam um marco na evolução paleogeográfica da bacia de deposição, caracterizando o confinamento em bacias isoladas na fase terminal da sedimentação Paraopeba, como trataremos detalhadamente no item "Paleogeografia", mais adiante.

UNIDADE VI - Siltitos e calcário preto Esta fácies é o equivalente estratigráfico do Membro "Lagoa do Jacaré" (Branco e Costa, op. cit.); ela é representada por siltitos homogêneos que encerram corpos lenticulares de calcário preto, com 2 ou mais quilômetros de extensão e espessura de 15 ou $20 \mathrm{~m}$.

A espessura dos sedimentos desta fácies é da ordem de $150 \mathrm{~m}$, produzindo o flanco abrupto que marca regionalmente a margem direita do curso médio do Rio São Francisco. Por sobre o bloco tectonicamente soerguido, na margem esquerda do mesmo rio (limitado ao norte à altura da localidade de São João das Missð̃es), o atual nível de erosão poupou apenas uma cobertura descontínua desta fácies, que encima regionalmente as elevações mais destacadas (Morro Mãe Joana, Itapiraçaba, etc.).

A alteração, agindo sobre os siltitos, acentua a homogeneidade dessa litologia, não sendo ignorados efeitos, tais como o carreamento da fração argilosa ou do conteúdo original em carbonatos que atuariam de maneira a exagerar esta homogeneidade.

O calcário preto é homogêneo, finamente cristalino, maciço ou laminado, apresentando-se localmente recristalizado, quando encerra agregados de cristais romboédricos de calcita preta.

Esta fácies apresenta-se progressivamente oolítica na continuidade norte do segmento Itacarambi-Januária, por 150 ou $200 \mathrm{~km}$, do Morro da Mesa e encerra ao sul, sudoeste e oeste do mesmo segmento (regiones de Sete Lagoas, Passos e Serra de São Domingos, respectivamente), estruturas de "esteiras" de algas e estromatólitos colunares.

ARENITO ARCOSEANO - FACIES URU$C U I A$ - Separados por uma discordância paralela dos conjuntos litológicos precedentemente descritos, os arenitos avermelhados e compactos desta fácies de idade admitida como cretácica apresentam-se sob a forma residual, coroando alguns dos relevos importantes da região, em ambas as margens do Rio São Francisco.

As espessuras desta unidade, habitualmente da or. dem de 5 ou $10 \mathrm{~m}$ na área estudada, podem atingir $90 \mathrm{~m}$ no Morro Itapiraçaba, próximo a Januária.

PALEOGEOGRAFIA Uma síntese da evolução paleogeográfica ao centro da Bacia Bambuí pode ser estabelecida, tomando-se a localidade de Itacarambi como referência:

- No segmento NE, apesar de preservarem as mesmas relações de espessura, os sedimentos da Formação Sete Lagoas sofreram sensíveis mudanças em seu meio de deposição, expressas pelo caráter exclusivamente oolítico de suas diversas unidades e pelo jogo sin-sedimentar notável de certas falhas; tais falhas, como confirmaram as sondagens realizadas pela Metamig S.A. em área da Serra do Parrela (A. C. Rabelo, com. pessoal), a oeste de Montalvânia (MG), produziram sobre seus comparti- 


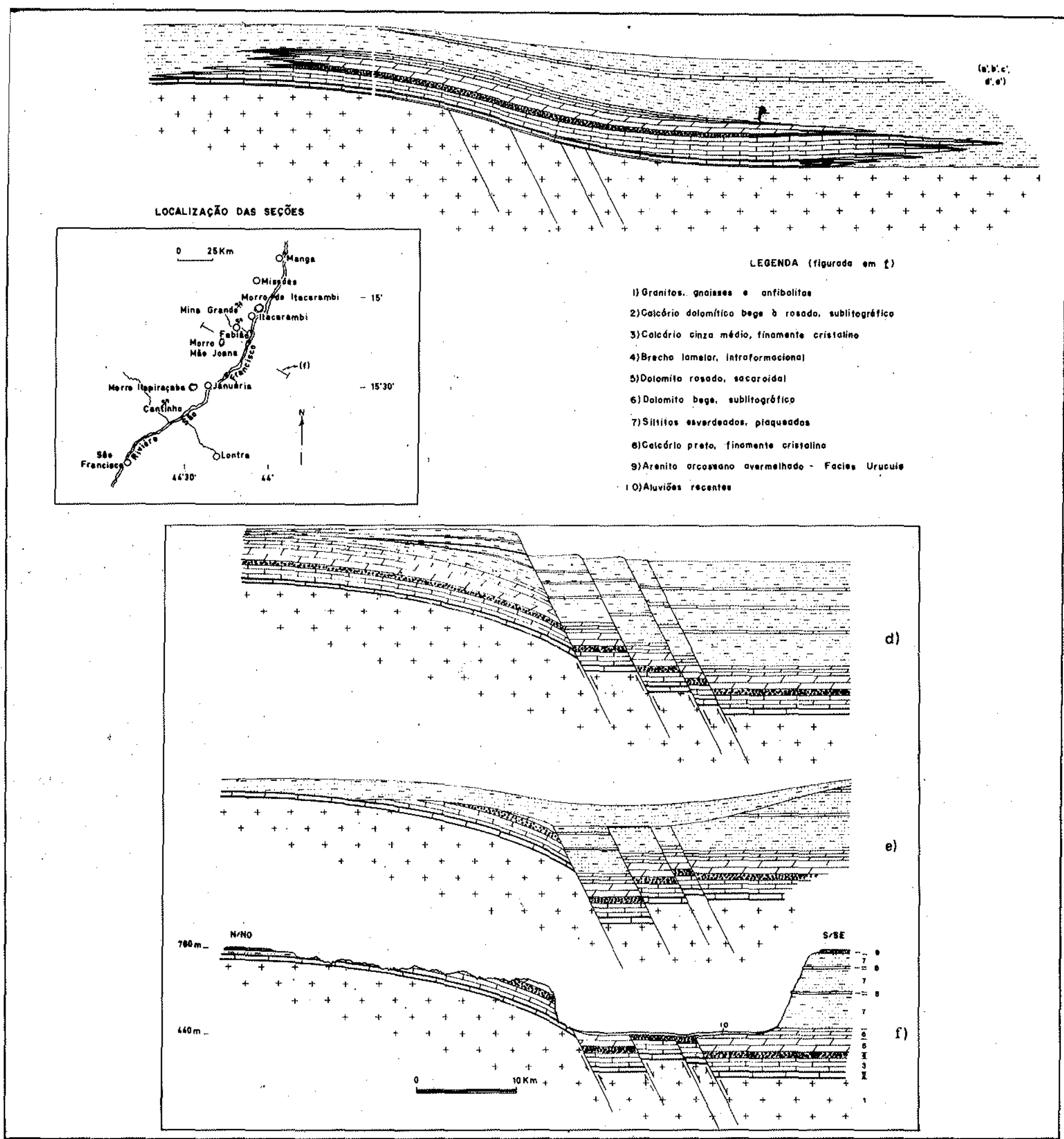

Figura 5 - Sintese tectônica e paleogeográfica ao centro da Bacia Bambuí. A evolução do embasamento como estrutura positiva, rontem. porânea da sedimentação, permite recompor os eventos: $a$ ) Deposição das unidades II e III (figuradas em $f$ ), em uma tacia com as din. snsões SE/NW mal definidas no campo, correspondendo aos bordos da área cizalhada da "geoclase". $b$ ) Reativação tectônica contemporânea de 4, instaladá sobre a área da estrutura positiva. c) Deposição, em ambientes infra a supralitoral, de 5 e 6 . $d$ ) Sedimentação reduzida de 7 e 8 , nas áreas sob a influência do alto-fundo regional. Legenda (figurada em $f-1$ ) Granitos, gnaisses e anfibolitos; 2) calcário dolomítico bege a rosado, sublitográfico; 3) calcário cinza-médio, finamente cristalino; 4) brecha lamelar, intraformacional; 5) dolomito rosado, sacaroidal: 6) dolomito bege, sublitográfico; 7) siltitos esverdeados, plaqueados; 8) calcário preto, finamente cristalino; 9) arenito arcoseano avermelhado - Fácies Urucuia; 10) aluvioes recentes 
mentos soerguidos os meios intermaré e supralitoral que deram origem às unidades III e IV, enquanto sobre os blocos rebaixados a Unidade VI recobre diretamente a Unidade II.

- A E/SE, a criação de uma bacia de caráter sensivelmente subsidente deu lugar à passagem lateral dos sedimentos da Formação Sete Lagoas, às litologias da Unidade V. A exata caracterização desta passagem de fácies (Fig. 5) só poderá ser estabelecida com a implantação de um programa de sondagens estratigráficas profundas, em perfis orientados perpendicularmente ao curso do Rio São Francisco.

- Na extensão SW da bacia, a montante do Rio São Francisco, a associação das formas de relevo em extensas "mesas" à ampla planície aluvial deste rio impede a visualização das relaçðes entre as duas principais fácies da Formação Paraopeba.

- A oeste, verifica-se um notável aumento na espessura dos sedimentos da Formação Paraopeba, passando de cerca de $400 \mathrm{~m}$ na regiăo estudada a mais de $1400 \mathrm{~m}$, ao longo da Serra de São Domingos (Dardenne, 1978b).

- Nenhum dado de natureza paleogeográfica pode ser obtido ao NW em razão da intensidade da ação erosiva que afetou esta área, responsável pela completa remoção das séries de cobertura do embasamento cristalino.

\section{REGIÃO ITACARAMBI-JANUARIA A orientaçăo} do curso do Rio São Francisco parece corresponder a uma direção bastante antiga na história do Craton do São Franicisco.

As unidades lito-estratigráficas I e II evidenciam, a partir de sua distribuição areal, uma deposição em bacia estreita e alongada, produzida originalmente pelo efeito acentuado de erosão sobre áreas cisalhadas do embasamento, nas vizinhanças imediatas da "geoclase" (Fig. 6-I).

Ao estabelecimento definitivo do mar transgressivo que deu origem à Unidade I, intercalaram-se vários eventos de exposição desses sedimentos ao meio subaéreo, como indicam as estruturas de fendas de dissecação (mud-cracks) descritas na região de Bonito (MG), na Fazenda Tamanduá (Lopes, 1979).

A profundidade extremamente reduzida do mar pré-cambriano que deu origem a esta unidade é confirmada pela presença de estruturas de arrasto (groovecasts) descritas na Fazenda Morro Vermelho, próxima ao Riacho da Cruz (Lopes, op. cit.). Tais estruturas testemunham por uma direção de deslocamento do corpo aquoso que deu origem às unidades basais carbonatadas, segundo NE/SW.

Neste contexto, a acentuação dos efeitos transgressivos responsáveis pela deposição da Unidade I produziria o meio de mar aberto, pouco profundo (como atestam as frequentes figuras de marcas de ondas simétricas), que deu origem à Unidade II.

Os múltiplos horizontes de brecha lamelar intraformacional que marcam o topo da Unidade II parecem ter sido produzidos pelas primeiras ações tectônicas responsáveis pela evolução paléogeográfica dos domínios de sedimentação definidos para as unidades sobrejacentes; tais brechas se fazem representar, tal como as unidades a elas superpostas, principalmente na margem esquerda do médio curso do Rio São Francisco.
Esses episódios de brechação teriam origem na evolução pulsátil do embasamento, nesta região, que culminou na maneira de introduzir $m$ dificaçðes ao meio de sedimentação, sob a forma de regressoes locais do nível do mar que produziram os meios infra a supralitoral, ue se encontram na origem das unidades III e IV (Fig. 6-II).

Os diferentes domínios de sedimentação individualizados desde a deposição da Unidade III podem ser identificados a partir da distribuição espacial das fácies por eles produzidos, das espessuras, ou do conteúdo em estruturas sedimentares das mesmas. Estes domínios são:

DOMíNIO A Trata-se de um domínio fortemente subsidente, produzido em um meio marinho relativamente profundo, comparável aos ambientes plataformais atuais. As áreas-fonte dos sedimentos clásticos a pelíticos depositados nos limites deste domínio parecem ter sido os terrenos então emersos do embasamento cristalino, ao N/NW da área estuḑada, ou, mais remotamente, de áreas desmontadas pela erosão na cadeia do Espinhaço, a S/SE.

Esse domínio corresponde, nos modelos conhecidos de sedimentação plataformal (Meissner, 1972; e Wilson, 1975; etc.), às zonas centrais de bacias em franca subsidência, com típica sedimentação dos componentes terrígenos.

DOMÍNIO B Neste domínio, os efeitos de subsidência foram reduzidos $\mathrm{e}$ suas dimensðes principais, definindo-o como uma plafaforma de declividade suave, acomodando-se à geometria da estrutura positiva do embasamento recém-criada. Esse meio de transiçăo deu lugar ao desenvolvimento das unidades III e IV, sobre uma faixa litoral bastante larga, estabelecendo um limite pouco preciso entre os domínios marinho e continental.

As condiçōes intermaré e até mesmo supralitoral prevalentes neste domínio são deduzidas, respectivamente, a partir das características de. dolomitização precoce (dolomitos lithoides stratifiés: ou "primários", Michard, 1967), sistematicamente verificando-se em presença de estruturas algais, o que é característico dos dolomitos que constituem a Unidade IV e, a partir da dolomitização essençialmente diagenética, desenvolvida sobre uma rocha produzida pela sedimentação de grãos grosseiros, de natureza carbonatada, geralmente distribuídos de maneira a configurar estruturas de laminações cruzadas (dolomie resédimentée ou detrital dolostones, Michard, op. cit.), como é o caso nos dolomitos da Unidade III.

DOMÍNIO C São incluídas como áreas correspondentes a este domínio as culminaçðes de caráter local, superimpostas às áreas do. Domínio $\mathrm{B}$.

Um meio "supersalino" (Aubague et al., 1966; e Macquar, 1968) de deposição, criado nos limites do Domínio $\mathrm{C}$, parece ter dado lugar ao desenvolvimento, no interior das unidades III e IV, de horizontes produzidos pela cristalização de sais em meio evaporítico, que seriam prontamente eliminados quando da evolução sin ou tardi-diagenética das rochas encaixantes, o que explicaria a presença de numerosos fronts de estilolização nelas observados. 


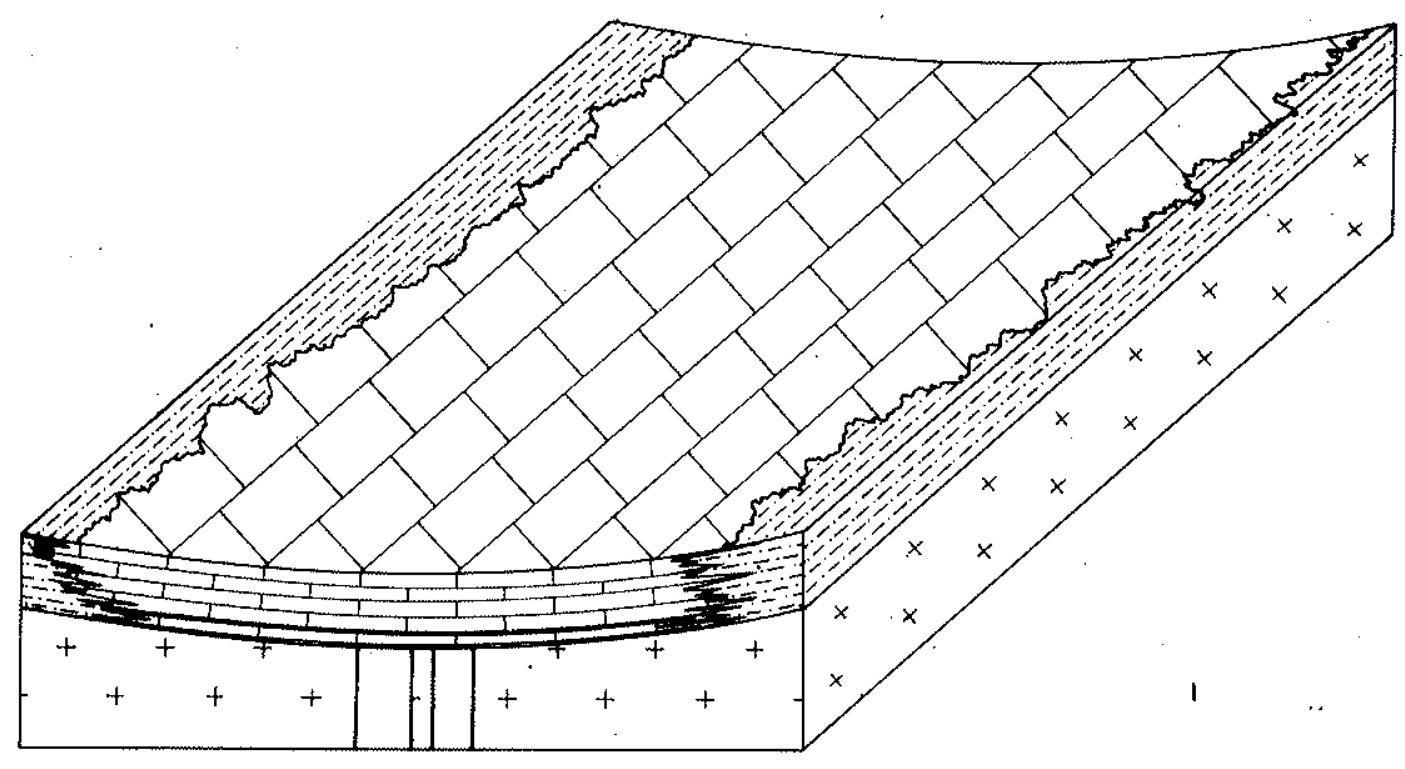

1

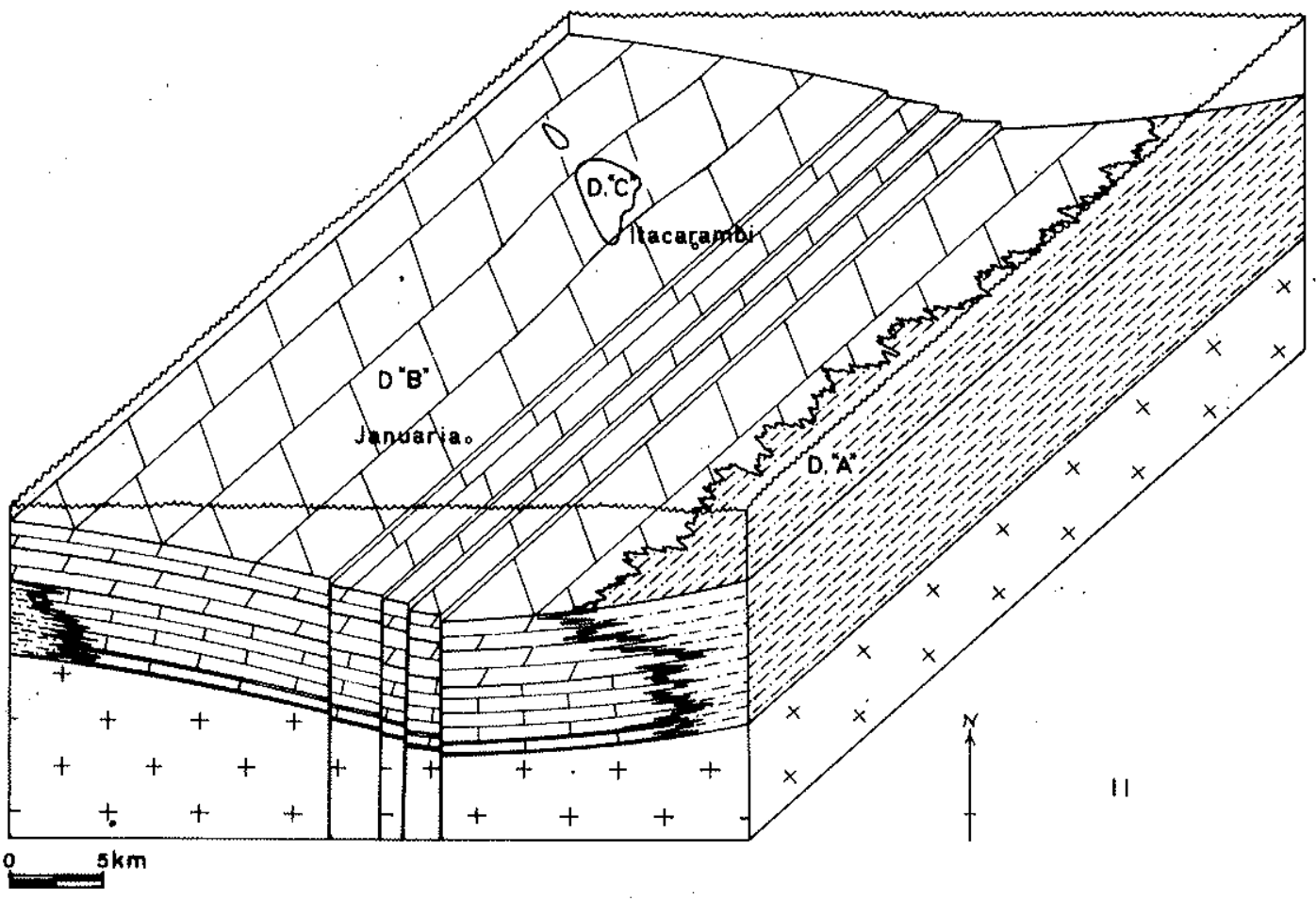

Figura 6 - Evolução paleogeográfica e estrutural da Formação Paraopeba, na porção central da bacia de deposição: repartição dos domínios de sedimentação $(A, B$ e $C)$ 
As áreas correspondentes a este domínio sofreram vários períodos de emersão; o principal deles é representado pelo topo da Unidade III, onde produziu uma superfície cárstica complexa (Fig. 3). A este efeito associase sobre as culminaçðes locais dos altos-fundos, como o exemplo do alto-fundo de Itacarambi, uma sedimentação reduzida (Figs. 5 e 6-II). Desta conjugação foram impostas importantes reduçōes na espessura dos horizontes dolomíticos; tais reduçðes podem alcançar cerca de $70 \%$ da Unidade III e $80 \%$ da Unidade IV, isto em relação às espessuras dessas unidades no Domínio $\mathrm{B}$ de sedimentação.

$\mathrm{O}$ Domínio $\mathrm{C}$ encerra um conjunto de culminaçðes locais expostas, como efeito da exageração da subida de seu substrato, à atuação da erosão em um meio preponderantemente supralitoral (Fig. 2).

As áreas desse domínio, limitadas ao interior do altofundo de Itacarambi, resumem-se a uma culminação principal, larga (cerca de $2 \mathrm{~km}$ ), com $4 \mathrm{~km}$ de comprimento, localizada em sua zona axial e às pequenas estruturas (com $500 \mathrm{~m}$ de comprimento) situadas nas vizinhanças do Janelão e na própria área da Mina do $\mathrm{Fa}$ bião, todas identificadas a partir de variaçðes na espessura das unidades III e/ou IV.

O Domínio $\mathrm{C}$ confirma o caráter precoce de sua evolução como estrutura positiva, em razão da redução, a seus limites, da espessura e do número de horizontes de brechas intraformacional do topo da Unidade II; eles teriam sido removidos pelos agentes erosivos, em ambiente supralitoral. Esta variação é a única observada em toda a extensão do Domínio B.

Enfim, os horizontes carbonatados horizontais $\mathrm{da}$ Formação Sete Lagoas apresentam regionalmente outros exemplos de estruturas positivas, de evolução contemporânea da sedimentação comparáveis às deste domínio, tal como na região de Montalvânia (descrita por K. Beurlen, 1973) e na Serra do Ramalho (BA) (descrita por M. A. Dardenne, 1979), onde se repetem as características do alto-fundo de Itacarambi no que se refere ao porte das estruturas, aos efeitos produzidos por reativações tectônicas tardias e, na região de Montalvânia, até mesmo a orientação espacial do alto-fundo (NW/SE) é rigorosamente análoga.

Assim, consideramos as áreas onde ocorrem estruturas como o alto-fundo de Itacarambi como correspondendo a zonas com uma manifestação particular da evolução tectônica do embasamento, talvez mesmo em conjugação com a "geoclase" do São Francisco.

Ao fim da deposição dos carbonatos da Formação Sete Lagoas e dos pelitos do Membro Serra de Santa Helena, estabeleceu-se sobre os domínios precedentemente descritos, em área de uma bacia pouco profunda, já parcialmente preenchida, uma sucessão de episódios de caráter transgressivo, anulados pelo acúmulo do material detrítico e reativados pela subsidência imposta por tais sedimentos, o que produziu as seqüências correlacionáveis ao Membro Lagoa do Jacaré que correspondem ao Domínio D.

No interior deste domínió de deposição, os corpos lenticulares de calcário preto seriam produzidos em um meio confinado de sub-bacias, nos últimos estágios da evolução - regressiva que marcou o topo das séries trabalhadas.
Os relevos correspondentes às áreas dos domínios $\mathrm{B} \mathrm{e}$ C impuseram uma sedimentação reduzida ao Membro Lagoa do Jacaré, em seus limites (Fig. 5). A influência de tais relevos, associada aos efeitos erosivos observados na área em apreço, pode, do mesmo modo, ser responsável pela presença reduzida de corpos do calcário preto, nos limites dos domínios B e C.

Submetidos aos efeitos de uma profunda exondação desde o Pré-Cambriano; os sedimentos da Formação Paraopeba serão, no Cretáceo Superior, recobertos por um meio de características continentais, deltaico, responsável pela repartição irregular dos arenitos da Fácies Urucuia.

TECTÔNICA A evolução tectônica dos terrenos estudados foi grandemente obliterada em seus vestígios, em razão da simultaneidade da sua evolução, com a sedimentação; desta evolução persistem os elementos:

SÍNTESE REGIONAL A importância da evolução tectônica na configuração geológica do médio São Francisco é colocada em relevo pela maioria dos autores que discorrem sobre esta regiaxo, apesar de fazerem-no de maneira empírica. Tạl fato é, em parte, justificado levando-se em conta a espessa cobertura aluvial deste rio, que se estende sobre uma faixa larga de 20 cu 30 $\mathrm{km}$, apresentando raros afloramentos das litolosigias subjacentes.

Calcados sobre os dados de uma série desses afloramentos, apresentaremos um esboço estrutural para o segmento Itacarambi-Januária. A simplicidade do modelo estrutural proposto condiz com a interpretação das estruturas, como as produzidas pelo efeito de reativação de antigos acidentes do embasamento.

São, deste modo, identificadas as seguintes "familias" de acidentes:

- Grandes falhas NE/SW: Estas falhas correspondem, por sua disposição, à orientação presumida da "geoclase" do São Francisco. Constituem uma família de acidentes que podem ser traçados de modo aproximativo. O feixe de falhas NE/SW é responsável pela orientação do curso do São Francisco e sua localização é inferida a partir do escalonamento de blocos, observado de NW para SE:

O primeiro bloco, rebaixado de cerca de $80 \mathrm{~m}$, estende-se desde o sopé da falésia da margem esquerda do Rio São Francisco até, pelo menos, o leito atual do mesmo rio. O "morro-testemunho", situado imediatamente ao norte de Itacarambi (Fig. 7), e a pequena elevação próxima à Lagoa Santo Antônio, cerca de $30 \mathrm{~km}$ ao sul da primeira referência, são as únicas exposiçðes de seqüências deste bloco.

As cotas da base do Arenito Urucuia, no Morro Itacarambi, são da ordem de $765 \mathrm{~m}$ e são em torno de 780 $\mathrm{m}$, coroando uma delgada camada de siltitos da Unidade V, no flanco oeste do Vale do São Francisco, o que comprova a anterioridade dos principais efeitos de rejogo das falhas desta família, ao Cretáceo Superior.

$O$ deslocamento imposto ao primeiro bloco se acentua a mais $50 \mathrm{~m}$, já na margem direita do São Francisco, como evidenciam os afloramentos ao nivel da planicie aluvial do mesmo rio ( $450 \mathrm{~m}$ de altitude média), do contato entre as unidades III e IV, entre as localidades de Pedras de Maria da Cruz e São Francisco. 


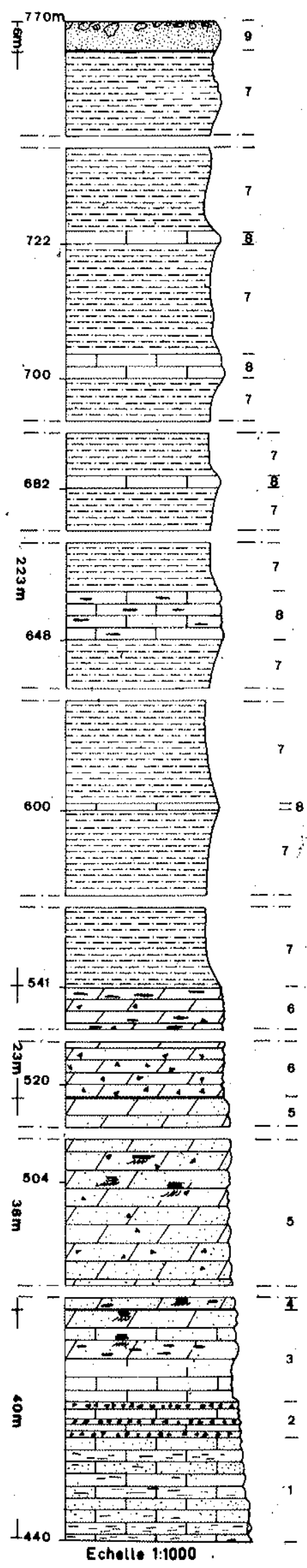

Figura 7 - Coluna litoestratigráfica do Morro Itacarambi: 1) caĺcário cinza-médio a claro, silicoso e com lâminas argilosas. Localmente a fluorita preenche fraturas submilimétricas. 2) Brecha lamelar intraformacional, com clastos de $5 \mathrm{~cm}$, em uma matriz sacaroidal cinza. 3) Horizonte transicional, grosseiramente cristalino, encerrando estruturas de laminaçóes cruzadas de baixo ângulo, além de lentes de chert preto. 4) Dolomito sacaroidal rosado, cristalino e homogêneo. 5) Dolomito rosado a avermelhado, com niveis bréchicos descontínuos e numerosas laminaçðes cruzadas. 6) Dolomito bege, sublitográfico, com numerosos horizontes de brecha lamelar intraformacional e, restritas ao topo, lentes de chert preto, além de "amas" de calcita espática. São frequentes as Jaminaçðes algais. 7) Siltitos argilosos avermelhados, homogêneos e alterados. 8) Calcário preto, finamente cristalino; encerra lentes de chert preto e é secionado por vênulos de calcita branca, acompanhada ocasionalmente pela fluorita. 9) Arenitos avermelhados, arcoseanos - Fácies Urucuia 
A existência de pequenas falhas de décrochement do sistema principal pode ser inferida a partir das mudanças abruptas na orientação do curso do Rio São Francisco e de alguns seus afluentes.

A horizontalidade geral das camadas deslocadas pelo sistema de falhas NE/SW e por seus satélites faz crer tratar-se de falhas normais, originalmente contínuas por centenas de quilômetros.

- Grande falha de São João das Missões: Este acidente prolonga-se de maneira bastante contínua, para oeste, a partir da localidade que lhe empresta o nome, sendo desprovido de acidentes satélites.

Trata-se de uma falha normal, de desenho algo arqueado mas grosso modo $\mathrm{E} / \mathrm{W}$, que coloca em contato litologias da Unidade IV, aos horizontes superiores da Unidade VI, evidenciando um rejeito mínimo da ordem de $100 \mathrm{~m}$; este acidente limita, ao norte, a grande estrutura positiva do embasamento, precedentemente caracterizada.

O compartimento norte deste acidente corresponde ao bloco abatido.

Os traços da reativação tectônica do Cretáceo são evidenciados sobre esta falha pela presença, ainda que residual, do Arenito Urucuia, rebaixado e preservado no compartimento norte deste acidente enquanto ele foi completamente removido pela erosão, no bloco soerguido.

A falha de São João das Missões pode, com reservas, ser considerada como tomando parte na evolução paleogeográfica dos terrenos estudados, desde que ela represente um limite, ao sul, para as fácies oolíticas dos calcários pretos da Unidade VI. As exposiçð̃es desta litologia são no Morro da Mesa, a alguns quilômetros ao norte desta falha, maciçamente oolíticas, guardando esta característica até, pelo menos, a região de Montalvânia.

\section{QUADRO LOCAL - EVOLUCÃO TECTÔNICA DO} ALTO-FUNDO DE ITACARAMBI Será sempre muito difícil dissociar-se, no conjunto dos acidentes produzidos pela evolução do alto-fundo de Itacarambi, o que advém de sua fase sin-sedimentar das fraturas que se sucederam, produzidas pelos múltiplos eventos de natureza rígida. Esta distinção é ainda mais difícil se levarmos em conta que as fraturas se superpuseram aos acidentes sin-sedimentares e estes, por sua vez, obedeceram à orientação das antigas falhas do embasamento em seu desenvolvimento.

Ainda, os dados de campo confirmam uma notável continuidade na sucessão dos eventos tectônicos ao longo de toda a história do alto-fundo de Itacarambi.

A descrição das principais famílias de falhas será, deste modo, feita a partir das feições finais produzidas por'elas apoiando-se, desde que possível, sobre critérios relativos de cronologia. São distintos, além dos acidentes isolados, três grupos principais de falhas:

- Falhas longitudinais: A estrutura positiva de Itacarambi é bordejada por falhas deste sistema, embora as más condições de afloramento observadas no flancó oeste desta estrutura apresente-nas ali, de maneira descontínua.

Esta familia de falhas normais faz-se representar por um segmento orientado a $\mathrm{N} 45^{\circ} \mathrm{W}$, no flanco leste, e por outro orientado a $\mathrm{N} 5{ }^{\circ} \mathrm{W}$, no flanco oeste da estrutura. Esses segmentos são interrompidos e deslocados por uma falha transversal, situada ao NW, próximo ao fechamento da estrutura dômica.

Sobre o flanco leste, um único acidente se desdobra em um feixe paralelo de falhas, progressivamente numerosas no extremo sul, na área entre a Mina Grande e o "Filäo" Ferreira.

O escalonamento dos blocos em horsts e grabens pode, nesta área, produzir rejeitos da ordem de $80 \mathrm{~m}$ (flanco oeste do vale do Córrego Cipoal, em frente à Mina Grande), de $100 \mathrm{~m}$ (entre as sondagens $256.60 \mathrm{e}$ $252.59+4 \mathrm{~S}+8,5 \mathrm{~W}$ ) ou, ainda, de $200 \mathrm{~m}$ (ponto 234-71 - mapa em escala 1:2 000) (Lopes, op. cit.).

No flanco oeste da estrutura positiva em questão, na área do Janelão, observa-se uma inflexão do segmento da falha longitudinal para a direção $S 45^{\circ} \mathrm{E}$.

- Falhas radiais: As falhas radiais apresentam-se dispostas transversalmente aos acidentes longitudinais, atuando geralmente como decrochements dos mesmos.

As falhas deste sistema não evidenciam nenhum rejeito vertical nos blocos por elas afetados, ou tais rejeitos são muito pouco importantes; entretanto, os deslocamentos horizontais desses blocos podem atingir uma centena de metros (pontos 250.62 a 254.71).

As falhas radiais são representadas sobre todo o domínio do alto-fundo de Itacarambi, fazendo-o de maneira mais contínua que as falhas do sistema longitudinal.

De sua disposição espacial à escala do alto-fundo concluiu-se que as falhas radiais se apresentam segundo um arranjo inverso do que seria esperado, se seu desenvolvimento se verificasse a partir de ações tectônicas de natureza compressiva; deste fato conclui-se que o conjunto dos acidentes radiais foram produzidos em resposta a movimentos ascensionais de uma porção restrita do embasamento cristalino.

- Sistema complexo de falhas: As falhas deste sistema limitam, ao sul, a área mineralizada da Mina Grande. Elas encontram-se dispostas segundo duas orientações bem definidas: $\mathrm{N} 30^{\circ} \mathrm{W}$ e $\mathrm{N} 45^{\circ} \mathrm{E}$.

O sistema complexo produz o efeito de escalonamento de blocos, além da disposição imbricada dos mesmos; o rejeito total imposto pelas falhas deste sistema é da ordem de $50 \mathrm{~m}$, mensurável a partir dos deslocamentos impostos aos níveis da base da Unidade IV desde a área da Mina Grande até o fundo do vale do Riacho Cipoal.

A identificação de campo das falhas do sistema complexo é facilitada em razão de os corpos de brecha cárstica preencherem sistematicamente tais descontinüidades, produzindo estruturas lineares bastante contínuas e geralmente aflorantes.

Quanto a sua natureza, a brecha cárstica é poligênica, encerrando clastos subarredondados de natureza petrográfica correspondente às litologias das unidades III, IV, de siltitos análogos aos das unidades V e VI e até mesmo das concreções ferruginosas, normalmente encontradas na base do Arenito Urucuia. Deste fato, a idade presumida desses corpos bréchicos é póscretácica.

O conjunto dos clastos desta brecha é embalado por uma matriz argilosa, amarelada; como preenchimento de cavidades desta matriz, ocorre a clacita fibrosa mar- 
rom, disposta em "paliçada", originária da evolução cárstica recente.

Não se exclui a possibilidade de que este sistema de falhas constitua a expressão particular e local do efeito de interseção das falhas do sistema radial, com as falhas longitudinais.

- Falha Fazenda Itabaiana: Esta falha, de disposição transversa às falhas longitudinais, produz o ef eito de um duplo fechamento da estrutura positiva de Itacarambi. Ela aflora ali, de maneira restrita, onde o permite a cobertura arenosa residual.

A dificuldade de avaliaçắo do rejeito imposto por esta falha resulta da ausência de horizontes de referência nas unidades que ela desloca. Ainda assim, um rejeito mínimo de $50 \mathrm{~m}$ (parte da Unidade III e toda a Unidade IV) se impõe.

Os dados expostos levam-nos a crer que a maioria dos sistemas de falhas apresenta inúmeros aspectos em comum, o que permite aproximar-lhes a evolução no tempo, ou até mesmo apresentá-los como desenvolvidos de maneira conjugada, Deste modo, os múltiplos even- tos de reativação teriam afetado, em bloco, a quase totalidade dos acidentes aos limites do alto-fundo.

CONClusōes Da análise conjunta dos dados apresentados, destacam-se as relações seguintes:

- Não é válido o empilhamento puro e simples do Membro Serra de Santa Helena sobre a Formação Sete Lagoas, pelo menos na região estudada. Em verdade, um recobrimento máximo da ordem de $100 \mathrm{~m}$, dos pelitos do topo da primeira sobre a segunda unidade, verifica-se (Figs. 2 e 7), sendo irrefutável a equivalência lateral da maior porção dessas fácies.

- Da caracterização regional das fácies carbonatadas e detríticas deve-se depreender, guardadas as proporções de um modelo epicontinental de sedimentação, que elas ocuparam, seja no bordo ou no centro da bacia, posiçōes paleogeográficas distintas no momento da deposição, mas posições estratigráficas perfeitamente correlacionáveis, embora jamais tenham-se apresentado de maneira contínua em toda a extensão da Bacia Paraopeba.

\section{BIBLIOGRAFIA}

AUBAgUe, M., PROUHeT; J. P. e SLANSKY, M. - 1966 - Caractérisation des milieux de sédimentation et recherche de nouveaux gîtes $\mathrm{Pb}-\mathrm{Zn}$ dans la zone caussenarde. Bull. B. R. G. M., n: 1 .

BEURLEN, K. - 1973 - Blei-zink-fluorit-Vererzungen in den Karbonatgeistei-en der Bambuj-Gruppe, Minas Gerais, Brasilien. Münster. Forsch, Geol. Paläont., vol. 31/32, p. 117-143.

BRANCO, J. J. R. e COSTA, M. T. da - 1961 - Roteiro da excursão Belo Horizonte-Brasília. XIV Congr. Bras. de Geologia. U.F.M.G., Inst, de Pesq. Radioat., n. 15, 25 pp.

CASSEDANNE, J. - 1972 - Les gîtes de plomb et de zinc du Brésil et leur répartition linéamentaire. Bull. B. R. G. M., 2: série, sect. II, n? 5, pp. 1-31.

CASSEDANNE, J. - 1973 - Paléogéographie et minéralisations de la zone Itacarambi-Vazante dans le Nord-Quest de l'Etat de Minas Gerais, Brésil. Mineralium Deposita, vol. 8, pp. 101-114.

DARDENNE, M. A. - 1978 - Sintese sobre a estratigrafia do Grupo Bambuf no Brasil Central. Anais do XXX Congr. Brasileiro de Geologia, vol. 2, pp. $597-610$.

DARDENNE, M. A. - 1978b-Zonaçăotectônica na borda ocidental do Cra. ton do Săo Francisco. Anais do XXX Congr. Brasileiro de Geologia, vol. 1, pp. 299-308.

DARDENNE, M. A. - 1979 - Les minéralisations plomb-zinc du Groupe Bambui et leur contexte géologique. Thése de Doctorat d'Etat, Universidade, de Paris VI, 275 pp.

DUNHAM, R. J. - 1962 - "Classification of carbonate rocks according to depositional texture". In: "Classif, of Carbonate Rocks" ed. por Ham, E. W., Am. Assoc. of Petrol. Geol, mem. 1, pp. 108-121.

LOGAN, B. W., REZAK, R. e GINSBURG, R. N. - 1964 - Classification and environmental significance of algal stromatolites, $J$, of Geol. 72 (1), 68-83.
LOPES, O.'F, - 1979 - Minéralisations en plomb, zinc et fluorine encaissées dans le Groupe Bambuí du Proterozoïque Superieur de la région d'ltacarambi (Minas Gerais-Brésil). Thèse de Doct. de $3^{\text {eme }}$ Cycle, Université de Paris VI, 190 pp.

FLEISCHER, R. e ROUTHIER, P. - 1970 - Quelques grands thèmes de la géologie du Brésil. Miscellanées géologiques et métallogéniques sur le Planalto. Sciences de la Terre, Tome XV, n: 1, pp. 45-102.

GODOY, M. P. de - 1958 - Estudos preliminares das ocorrências minerais do grupo de Pandeiros. Revista da Escola de Minas, Ouro Preto, vol. 21, pp. 113-118.

GUIMARÃES, D. - 1964 - Geologia do Brasil. Mem. do Dept. Nac. da Produção Mineral, n: 1, $674 \mathrm{pp}$.

MACQUAR, J.-C. - 1968 - Contribution à l'étude géologique et metallogénique de la bordure méridionale des Cévennes. Les trias de la région des Malines (Gard). Thèse de $3^{\text {eme }}$ Cycle, Université de Paris VI, t. 1, 122 pp.

MEISSNER, F. F. - 1972 - "Cyclic sedimentation in Middle Permian strata of the Permian Basin, West Texas and New Mexico", In: "Cyclic Sedimentation in the Permian Basin" ed. por Elam, J. C. e Chuber, S. West Texas Geol. Soc. Midland, 2a edição, pp. 203-232.

MICHARD, A. - 1969 - Les dolomies, une revue. Bull. du Serv. de la Carte Géol. d'Alsace el de Lorraine. T. 22, fasc. 1, pp. 1-92.

PFLUG, R, e SCHÖLL, W. U. - 1975 - Proterozoic glaciations in eastern Brazil: a review. Geol. Rundschau 64 (1), 287.299.

WILSON, J. L. - 1975 _Carbonate Facies in Geologic History" Springer Verlag, $471 \mathrm{pp}$. 